\title{
Fiorella de Rosis, in memoriam
}

Fiorella de Rosis, an internationally recognized researcher in user modeling and adaptation, died on Wednesday, July 30, 2008 at the age of 67. She was a pioneer in the field of affective computing, and a dear friend who is sorely missed.

Fiorella received a $\mathrm{PhD}$ in physics in 1965 from the University of Roma "La Sapienza" in the celebrated Institute of Enrico Fermi and his heirs. Her dissertation was in theoretical computer science. Her tutor, Corrado Bohm, taught her the importance of formal methods in informatics, and this influenced her work throughout her career. In the late 60 s and early 70 s, Fiorella joined a multidisplinary group of young Italian scholars interested in public health. When Italy adopted its health reform in 1978, Fiorella, as well as other Italian scientists working in public health, had many expectations on the potential of epidemiology and the use of informatics in medicine. Later, Fiorella became disappointed by the inability of epidemiology to face real problems in Italian society, and devoted the last 15-20years of her life to the field of informatics.

Fiorella's work in informatics is best known for her contributions to affective computing. She was a leader in research on modeling emotions and constructing embodied animated agents. Not only did she publish numerous articles on affect in humancomputer interfaces, but she also advanced the field via her leadership in organizing workshops and editing special journal issues devoted to affective computing. Most recently, she was a guest editor of a 2007 special issue of User Modeling and UserAdapted Interaction. During her long academic career, she also produced key contributions in intelligent user interfaces, focusing on user-adapted generation of natural language and multimedia messages, uncertainty in user models, and the presentation of medical explanations and clinical guidelines.

Between 1965 and 1972, Fiorella was the director of the division for technical assistance to member States of the Intergovernmental Bureau for Information Technology (IBIT), an agency promoted by UNESCO. For some years, as Ricercatore of the Italian research council Consiglio Nazionale delle Ricerche (CNR), she was responsible for the Special Program on Biomedical Technologies. Her publications in these years 
focused on pattern recognition, signal processing and their applications to medicine, and epidemiology. In 1980, Fiorella left CNR and became a Professor of Computer Science at the University of Bari. During the course of her career, she mentored many students who have become established researchers. She was a member of the ACM, of the International Society for Research on Emotions, of the European Network of Excellence on Emotions (HUMAINE), and served on the editorial boards of UMUAI (Since 2000) and of Recent Patents on Computer Science. Fiorella was also Program Co-Chair with Albert Corbett of the 9th International Conference on User Modeling in 2003.

For us, however, Fiorella was not only a respected colleague but also a true and loyal friend, and we will miss both the researcher and the person.

The UMUAI Editorial Board 